\title{
ANALISIS PERHITUNGAN METODE MOORA DALAM PEMILIHAN SUPPLIER BAHAN BANGUNAN DI TOKO MEGAH GRACINDO JAYA
}

\author{
Sri Wardani ${ }^{1}$, Iin Parlina ${ }^{2}$, Ahmad Revi ${ }^{3}$ \\ ${ }^{1,3}$ Mahasiswa Sistem Informasi, STIKOM Tunas Bangsa Pematangsiantar \\ ${ }^{2}$ Dosen AMIK Tunas Bangsa Pematangsiantar \\ 1,2,3 Jln.Jenderal Sudirman Blok A No.1/2/3 Pematangsiantar \\ sriwardani90804@gmail.com, iin@amiktunasbangsa.ac.id, ahmadrevi98@gmail.com
}

\begin{abstract}
Abstrak - Sistem pendukung keputusan didefinisikan sebagai sebuah sistem yang dimaksudkan untuk mendukung para pengambil keputusan manajerial dalam situasi situasi tertentu. Sistem pendukung keputusan dimaksudkan untuk menjadi alat bantu bagi para pengambil keputusan untuk memperluas kapabilitas mereka, namun tidak untuk menggantikan penilaian mereka. Penentuan supplier merupakan kegiatan strategis, terutama apabila supplier tersebut akan memasok item yang penting dan akan digunakan dalam jangka panjang. Untuk mendapatkan bahan baku yang efektif dan efisien maka Megah Gracindo Jaya harus melakukan pemilihan supplier yang handal sesuai dengan kriteria yang dibutuhkann oleh perusahaan. Salah satu metode dalam pemilihan keputusan dalah metode Multi-Objective Optimization by Ratio Analysis Atau biasa disingkat dengan metode MOORA. Metode MOORA adalah metode yang memiliki perhitungan dengan kalkulasi yang minimum dan sangat sederhana. Dari penelitian yang dilakukan dengan metode MOORA didapatkan bahwa A3 adalah supplier yang paling tepat.
\end{abstract}

Keywords — Sistem Pendukung Keputusan, Supplier, Multi-Objective Optimization by Ratio Analysis (MOORA)

\section{PENDAHULUAN}

Melihat perkembangan dunia usaha yang sedemikian cepatnya mengakibatkan perusahaan berlomba-lomba menjadi yang terbaik untuk memenuhi permintaan pasar global. Megah Gracindo Jaya adalah sebuah toko penyedia bahan-bahan bangunan berskala kecil menengah. Beragamnya permintaan akan bahan-bahan bangunan dari konsumen menyebabkan Megah Gracindo Jaya harus selalu menyediakan dan memberikan pelayanan yang terbaik bagi para konsumennya. Dalam usaha menenangkan persaingan dimata para konsumen Megah Gracindo Jaya menggunakan berbagai cara diantaranya meningkatkan kepuasan pelanggan melalui produk berkualitas, ketepatan waktu pengiriman dan efisiensi biaya.

Pemilihan supplier merupakan salah satu hal yang penting dalam aktivitas pembelian bagi perusahaan, karena pemilihan supplier ini sangat berpengaruh pada harga jual, kualitas dan ketersediaan suatu produk. Oleh karena itu, setiap perusahaan perlu menilai supplier secara cermat dan tepat. Penentuan supplier merupakan kegiatan strategis, terutama apabila supplier tersebut akan memasok item yang penting dan akan digunakan dalam jangka panjang. Untuk mendapatkan bahan baku yang efektif dan efisien maka Megah Gracindo Jaya

Sistem pendukung keputusan didefinisikan sebagai sebuah sistem yang dimaksudkan untuk mendukung para pengambil keputusan manajerial dalam situasi situasi tertentu. Sistem pendukung keputusan dimaksudkan untuk menjadi alat bantu bagi para pengambil keputusan untuk memperluas kapabilitas harus melakukan pemilihan supplier yang handal sesuai dengan kriteria yang dibutuhkann oleh perusahaan. Hal mendasari penelitian ini adalah untuk membantu Megah Gracindo Jaya dalam membuat sebuah keputusan dalam usaha untuk suppliersupplier yang dapat menguntungkan dan memberikan pelayanan jangka panjang terhadap Megah Gracindo Jaya itu sendiri.

Salah satu metode dalam pemilihan keputusan dalah metode Multi-Objective Optimization by Ratio Analysis Atau biasa disingkat dengan metode MOORA. Metode MOORA adalah metode yang memiliki perhitungan dengan kalkulasi yang minimum dan sangat sederhana. Metode ini memiliki tingkat selektifitas yang baik dalam menentukan suatu alternatif. Pendekatan yang dilakukan MOORA didefinisikan sebagai suatu proses secara bersamaan guna mengoptimalkan dua atau lebih yang saling bertentangan pada beberapa kendala [1]. Diharapkan dari penelitian ini dapat memberikan sebuah cara pemilihan yang ideal kepada toko Megah Gracindo Jaya dalam memilih supplier-supplier yang akan menjadi mitra dagang.

\section{TINJAUAN PUSTAKA}

\section{A. Sistem Pendukung Keputusan}

Sistem pendukung keputusan didefinisikan sebagai sebuah sistem yang dimaksudkan untuk mendukung para pengambil keputusan manajerial dalam situasi situasi tertentu. Sistem pendukung keputusan dimaksudkan untuk menjadi alat bantu bagi para pengambil keputusan untuk memperluas kapabilitas mereka, namun tidak untuk menggantikan penilaian mereka [2]. SPK merupakan penggabungan sumber-sumber kecerdasan individu dengan kemampuan komponen untuk memperbaiki kualitas keputusan [3]. 
Sistem Pendukung Keputusan (SPK) adalah salah satu cara mengorganisir informasi yang dimaksudkan untuk digunakan dalam membuat keputusan. Ada yang mendefinisikan bahwa system pendukung keputusan merupakan suatu pendekatan untuk mendukung pengambilan keputusan.Sistem pendukung keputusan menggunakan data, memberikan antarmuka pengguna yang mudah dan dapat menggabungkan pemikiran pengambil keputusan [4].

\section{B. Manajemen Rantai Pasokan}

Manajemen rantai pasokan atau Supply Chain Management merupakan kegiatan pengelolaan kegiatankegiatan dalam rangka memperoleh bahan mentah, mentransformasikan bahan mentah tersebut menjadi barang dalam proses dan barang jadi, dan mengirimkan produk tersebut ke konsumen melalui sistem distribusi. Kegiatankegiatan ini mencakup fungsi pembelian tradisional ditambah kegiatan-kegiatan lainnya yang penting bagi hubungan antara pemasok dengan distributor [5].

C. Pemilihan Supplier

Pemilihan supplier biasanya mempertimbangkan kualitas dari produk, service/pelayanan dan ketepatan waktu pengiriman adalah hal yang penting, meskipun ada beberapa faktor lain yang harus dipertimbangkan. Dengan banyak kriteria-kriteria yang ada dalam pemilihan supplier, namun keputusan dalam penentuan kriteria yang akan digunakan dalam suatu perusahaan ditentukan oleh perusahaan itu sendiri. Perusahaan akan memilih beberapa kriteria yang ada, pemilihan kriteria biasanya tergantung dari item-item bahan baku yang dipasok ke perusahaan [6].

\section{METOde PENELITIAN}

Metode Multi-Objective Optimization by Ratio Analysis ( MOORA) adalah metode yang diperkenalkan oleh Brauers dan Zavadkas (2006). Metode yang relatif baru ini pertama kali digunakan oleh Brauers dalam suatu pengambilan dengan multi- kriteria. Metode MOORA memiliki tingkat fleksibilitas dan kemudahan untuk dipahami dalam memisahkan bagian subjektif dari suatu proses evaluasi kedalam kriteria bobot keputusan dengan beberapa atribut pengambilan keputusan [7].

Metode MOORA mudah dipahami dan fleksibel dalam memisahkan objek hingga proses evaluasi kriteria bobot keputusan. Metode MOORA juga memiliki tingkat selektifitas yang baik karena dapat menentukan tujuan dan kriteria yang bertentangan, yaitu kriteria yang bernilai menguntungkan (Benefit) atau yang tidak menguntungkan (Cost) [8].

Langkah - langkah penyelesaian masalah menggunakan metode MOORA, antara lain [9]:
1. Pembentukan Matriks

$$
x i j=\begin{array}{ccc}
X 11 & X 12 & X 1 n \\
X 21 . & X 22 & X 2 n \\
X m 1 & . & . \\
& X m 2 & X m n
\end{array}
$$

$\mathrm{x}$ adalah nilai kriteria masing-masing kriteria yang direpresentasikan sebagai matriks.

2. Menetukan Matriks Normalisasi

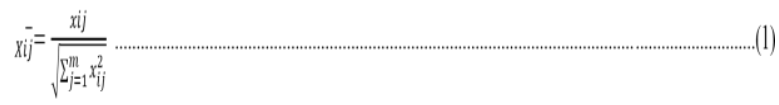

Rasio Xij menunjukan ukuran ke i dari alternatif pada kriteria ke j, m menunjukan banyaknya jumlah alternatif dan n menunjukan jumlah kriteria. Brauers et al. (2008) menyimpulkan bahwa untuk denominator, pilihan terbaik dari akar kuadrat dari penjumlahan kuadrat dari setiap alternatif perkriteria.

\section{Menentukan Matriks Normalisasi terbobot}

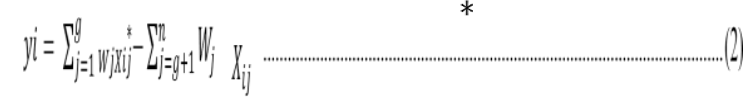

Dalam beberapa kasus, sering mengamati bahwa beberapa kriteria lebih penting daripada lainnya. Untuk menandakan bahwa sebuah kriteria lebih penting, itu bisa dikalikan dengan bobot yang sesuai. Dimana $\mathrm{Wj}$ adalah bobot dari kriteria $\mathrm{ke}-\mathrm{j}$.

4. Menentukan Nilai Preferensi

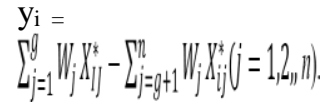

Dengan demikian, alternatif terbaik memiliki nilai yi tertinggi, sedangkan alternatif terburuk memiliki nilai $\mathrm{y}_{\mathrm{j}}$ terendah.

\section{HASIL DAN PEMBAHASAN}

Pada permasalahan ini akan di bahas pemilihan supplier bahan bangunan dengan menggunakan metode MOORA, adapun langkah pertama yang akan di lakukan dalam melakukan perhitungan maka harus menentukan kriteria-kriteria penilaian yang sudah di tentukan. Kriteriakriteria yang dipakai dapat dilihat pada table berikut : 
TABEL I

PENDEFINISIAN KRITERIA

\begin{tabular}{|l|l|l|l|}
\hline Kriterian & Keteragan & $\begin{array}{l}\text { Nilai } \\
\text { Bobot }\end{array}$ & Jenis \\
\hline C1 & Harga & $25 \%$ & Benefit \\
\hline C2 & Kualiatas & $25 \%$ & Benefit \\
\hline C3 & Pelayanan & $15 \%$ & Benefit \\
\hline C4 & Ketepatan Pengiriman & $20 \%$ & Benefit \\
\hline C5 & Ketepatan Jumlah & $15 \%$ & Benefit \\
\hline
\end{tabular}

Kriteria yang memakai penilaian bukan nilai angka akan di sesuaikan dengan skala penilaian seperti di bawah ini :

$\begin{array}{ll}\text { Sangat Baik } & =5 \\ \text { Baik } & =4 \\ \text { Cukup } & =3\end{array}$

Kurang $=2$

Adapun keterangan untuk kriteria harga sebagai berikut :

sesuai dengan kualitas $=5$

cukup sesuai $\quad=4$

Kurang sesuai $\quad=3$

Tidak sesuai $\quad=2$

Penilaian pada setiap kriteria tentunya berdasarkan

kepuasan daripada toko Megah Gracindo Jaya.

Data Penilaian Alternati berdasarkan kriteria di atas dapat dilihat pada tabel berikut :

TABEL II

PEMBERIAN NILAI SETIAP ALTERNATIF

\begin{tabular}{|c|c|c|c|c|c|}
\hline & & & & & \\
\hline Alternatif & $\mathrm{C} 1$ & $\mathrm{C} 2$ & C3 & $\mathrm{C} 4$ & $\mathrm{C} 5$ \\
\hline A1 & $\begin{array}{l}\text { Cukup } \\
\text { sesuai }\end{array}$ & Baik & $\begin{array}{c}\text { Sangat } \\
\text { baik }\end{array}$ & Baik & $\begin{array}{c}\text { Sangat } \\
\text { baik }\end{array}$ \\
\hline A2 & $\begin{array}{l}\text { Sesuai } \\
\text { dengan } \\
\text { kualitas }\end{array}$ & Baik & Baik & Baik & $\begin{array}{c}\text { Sangat } \\
\text { baik }\end{array}$ \\
\hline A3 & $\begin{array}{l}\text { Sesuai } \\
\text { dengan } \\
\text { kualitas }\end{array}$ & $\begin{array}{c}\text { Sangat } \\
\text { baik }\end{array}$ & Baik & $\begin{array}{c}\text { Sangat } \\
\text { baik }\end{array}$ & $\begin{array}{c}\text { Sangat } \\
\text { baik }\end{array}$ \\
\hline A4 & $\begin{array}{l}\text { Kurang } \\
\text { sesuai }\end{array}$ & Cukup & $\begin{array}{c}\text { Sangat } \\
\text { baik }\end{array}$ & Baik & Baik \\
\hline A5 & $\begin{array}{l}\text { Sesuai } \\
\text { dengan } \\
\text { kualitas }\end{array}$ & $\begin{array}{c}\text { Sangat } \\
\text { baik }\end{array}$ & Baik & Cukup & Baik \\
\hline
\end{tabular}

Adapaun di peroleh perubahan alternatif sebagai berikut :

TABEL III

PERUBAHAN NILAI SETIAP ALTERNATIF

\begin{tabular}{|l|l|l|l|l|l|}
\hline Alternatif & C1 & C2 & C3 & C4 & C5 \\
\hline A1 & 4 & 4 & 5 & 4 & 5 \\
\hline
\end{tabular}

\begin{tabular}{|l|l|l|l|l|l|}
\hline A2 & 5 & 4 & 4 & 4 & 5 \\
\hline A3 & 5 & 5 & 4 & 5 & 5 \\
\hline A4 & 3 & 3 & 5 & 4 & 4 \\
\hline A5 & 5 & 5 & 4 & 3 & 4 \\
\hline
\end{tabular}

Berdasarkan data di atas dapat diperoleh matriks keputusan dalam tabel berikut :

TABEL IV

MATRIKS KEPUTUSAN

\begin{tabular}{|c|c|c|c|c|}
\hline 4 & 4 & 5 & 4 & 5 \\
\hline 5 & 4 & 4 & 4 & 5 \\
\hline 5 & 5 & 4 & 5 & 5 \\
\hline 3 & 3 & 5 & 4 & 4 \\
\hline 5 & 5 & 4 & 3 & 4 \\
\hline
\end{tabular}

C

$: \sqrt{4^{2}+5^{2}+5^{2}+3^{2}+5^{2}}$

: 10,000

$\mathrm{A}_{11}: 4 / 10,000$

: 0,4000

$\mathrm{A}_{21}: 5 / 10,000$

: 0,5000

$\mathrm{A}_{31}: 5 / 10,000$

$: 0,5000$

$\mathrm{A}_{41}: 3 / 10,000$

: 0,3000

$\mathrm{A}_{51}: 5 / 10,000$

: 0,5000

$\mathrm{C} 2$

$: \sqrt{4^{2}+4^{2}+5^{2}+3^{2}+5^{2}}$

: 9,5394

$\mathrm{A}_{11}: 4 / 9,5394$

: 0,4193

$\mathrm{A}_{21}: 4 / 9,5394$

: 0,4193

$\mathrm{A}_{31}: 5 / 9,5394$

: 0,5241

$\mathrm{A}_{41}: 3 / 9,5394$

: 0,3145

$\mathrm{A}_{51}: 5 / 9,5394$

: 0,5241

C3

$: \sqrt{5^{2}+4^{2}+4^{2}+5^{2}+4^{2}}$

: 9,8995

$\mathrm{A}_{11}: 5 / 9,8995$

: 0,5051

$\mathrm{A}_{21} \quad: 4 / 9,8995$ 


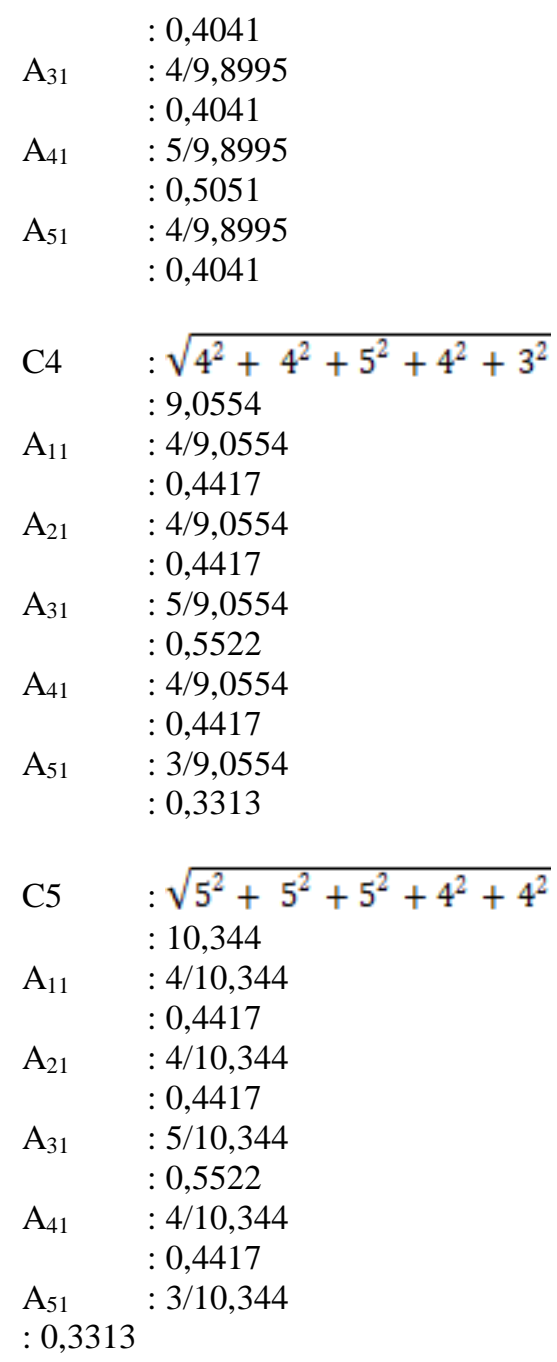

Maka dapat dilihat matriks ternormalisasi berikut, yaitu :

TABEL V

MATRIKS NORMALISASI

\begin{tabular}{|l|l|l|l|l|}
\hline 0,4000 & 0,4193 & 0,5051 & 0,4417 & 0,4834 \\
\hline 0,5000 & 0,4193 & 0,4041 & 0,4417 & 0,4834 \\
\hline 0,5000 & 0,5241 & 0,4041 & 0,5522 & 0,4834 \\
\hline 0,3000 & 0,3145 & 0,5051 & 0,4417 & 0,3867 \\
\hline 0,5000 & 0,5241 & 0,4041 & 0,3313 & 0,3867 \\
\hline
\end{tabular}

Selanjutnya menghitung matriks ternormalisasi terbobot :

$$
\begin{aligned}
\mathrm{C}_{1}=\mathrm{A}_{11}: 0,25 \times 0,4000=0,1000 \\
\mathrm{~A}_{21}: 0,25 \times 0,5000=0,1250 \\
\mathrm{~A}_{31}: 0,25 \times 0,5000=0,1250 \\
\mathrm{~A}_{41}: 0,25 \times 0,3000=0,0750 \\
\mathrm{~A}_{51}: 0,25 \times 0,5000=0,1250 \\
\mathrm{C}_{2}=\mathrm{A}_{11}: 0,25 \times 0,4193=0,1048
\end{aligned}
$$

$\mathrm{A}_{21}: 0,25 \times 0,4193=0,1048$

$\mathrm{A}_{31}: 0,25 \times 0,5241=0,1310$

$\mathrm{A}_{41}: 0,25 \times 0,3145=0,0786$

$\mathrm{A}_{51:}: 0,25 \times 0,5241=0,1310$

$\mathrm{C}_{3}=\mathrm{A}_{11}: 0,15 \times 0,5051=0,0758$

$\mathrm{A}_{21}: 0,15 \times 0,4041=0,0606$

$\mathrm{A}_{31}: 0,15 \times 0,4041=0,0606$

$\mathrm{A}_{41:}: 0,15 \times 0,5051=0,0758$

$A_{51}: 0,15 \times 0,4041=0,0606$

$\mathrm{C}_{4}=\mathrm{A}_{11}: 0,20 \times 0,4417=0,0883$

$\mathrm{A}_{21}: 0,20 \times 0,4417=0,0883$

$\mathrm{A}_{31}: 0,20 \times 0,5522=0,1104$

$\mathrm{A}_{41}: 0,20 \times 0,4417=0,0883$

$\mathrm{A}_{51}: 0,20 \times 0,3313=0,0663$

$$
\begin{aligned}
\mathrm{C}_{5}=\mathrm{A}_{11}: 0,15 \times 0,4834=0,0725 \\
\mathrm{~A}_{21}: 0,15 \times 0,4834=0,0725 \\
\mathrm{~A}_{31}: 0,15 \times 0,4834=0,0725 \\
\mathrm{~A}_{41}: 0,15 \times 0,3867=0,0580
\end{aligned}
$$

$\mathrm{A}_{51:} 0,15 \times 0,3867=0,0580$

Maka hasilnya dapat dilihat pada matriks di bawah ini :

TABEL VI

HASIL MATRIKS TERNORMALISASI TERBOBOT

\begin{tabular}{|c|c|c|c|c|}
\hline 0,1000 & 0,1048 & 0,0758 & 0,0883 & 0,0725 \\
\hline 0,1250 & 0,1048 & 0,0606 & 0,0883 & 0,0725 \\
\hline 0,1250 & 0,1310 & 0,0606 & 0,1140 & 0,0725 \\
\hline 0,0750 & 0,0786 & 0,0758 & 0,0883 & 0,0580 \\
\hline 0,1250 & 0,1310 & 0,0606 & 0,0663 & 0,0580 \\
\hline
\end{tabular}

Selanjutnya pencarian nilai Yi seperti berikut :

TABEL VII

PENCARIAN NILAI Yi

\begin{tabular}{|c|l|c|c|}
\hline Alternatif & Max $\left(\mathrm{C}_{1}+\mathrm{C}_{2}+\mathrm{C}_{3}+\mathrm{C}_{4}+\mathrm{C}_{5}\right)$ & $\begin{array}{c}\text { Min } \\
(0)\end{array}$ & $\begin{array}{c}\mathrm{Yi}= \\
\mathrm{Max}- \\
\mathrm{Min}\end{array}$ \\
\hline A1 & $\begin{array}{l}(0,1000+0,1048+0,0758+ \\
0,0883+0,0725)\end{array}$ & 0 & 0.4414 \\
\hline A2 & $\begin{array}{l}(0,1250+0,1048+0,0606+ \\
0,0883+0,0725)\end{array}$ & 0 & 0,4512 \\
\hline A3 & $\begin{array}{l}(0,1250+0,1310+0,0606+ \\
0,1140+0,0725)\end{array}$ & 0 & 0,5031 \\
\hline A4 & $\begin{array}{l}(0,0750+0,0786+0,0758+ \\
0,0883+0,0580)\end{array}$ & 0 & 0,3757 \\
\hline A5 & $\begin{array}{l}(0,1250+0,1310+0,0606+ \\
0,0663+0,0580)\end{array}$ & 0 & 0,4409 \\
\hline
\end{tabular}


Adapun hasil perangkingan seperti berikut :

TABEL VIII

PERANGKINGAN

\begin{tabular}{|c|c|c|}
\hline Alternatif & Yi & Rangking \\
\hline $\mathrm{A}_{1}$ & 0,4414 & 3 \\
\hline $\mathrm{A}_{2}$ & 0,4512 & 2 \\
\hline $\mathrm{A}_{3}$ & 0,5031 & 1 \\
\hline $\mathrm{A}_{4}$ & 0,3757 & 5 \\
\hline $\mathrm{A}_{5}$ & 0,4409 & 4 \\
\hline
\end{tabular}

Dari peroses tersebut maka dapat di hasilkan bahwa $\mathrm{A}_{3}$ adalah alternatif terbaik.

\section{KESIMPULAN DAN SARAN}

Kesimpulan yang dapat di ambil dari hasil penelitian bahwa kita dapat menggunakan metode Multi-Objective Optimization by Ratio Analysis(MOORA) untuk menentukan nilai bobot

\section{REFERENSI}

[1] S. Rokhman, I. F. Rozi, and R. A. Asmara, "Pengembangan Sistem Penunjang Keputusan Penentuan UKT Mahasiswa Dengan Menggunakan Metode MOORA Studi Kasus Politeknik Negeri Malang," J. Inform. Polinema, vol. 3, pp. 36-42, 2017.

[2] Habibah Jayanti Damanik, I. Parlina, H. S. Tambunan, and E. Irawan, "Sistem Pendukung Keputusan dalam Seleksi Penyiar Radio Boss FM 102.8 Pematangsiantar Menggunakan Metode ELECTRE," Konf. Nas. Teknol. Inf. dan Komput., vol. I, pp. 38-44, 2017.

[3] Vita, E. S. Astuti, and R. A. Asmara, "PASKIBRAKA MENGGUNAKAN METODE TOPSIS," J. Inform. Polinema, pp. 51-55.

[4] S. Sundari, A. Wanto, Saifullah, and Indra Gunawan, "Sistem Pendukung Keputusan Dengan Menggunakan Metode Electre Dalam Merekomendasikan Dosen Berprestasi Bidang Ilmu Komputer (Study Kasus di AMIK \& STIKOM Tunas Bangsa)," Semin. Nas. Multi Disiplin Ilmu, pp. 1-6, 2017.

[5] I. I. Alifatin, "Analisis Pemilihan Supplier Dengan Metode Analisis Hirarki Proses Pada Toko Pertanian dan Bangunan UD Mansur Jalan Raya Papar Pare Kediri," Artik. Skripsi Univ. Nusant. PGRI Kediiri, pp. 1-15, 2016.

[6] S. Widiyanesti, R. Setyorini, L. Cost, and Q. Respon, "No Title."

[7] M. Ashari and F. Mintarsih, "Aplikasi Pemilihan Bibit Budidaya Ikan Air Tawar dengan Metode MOORA - Entropy," J. Sist. Inf., vol. 5341, pp. 63-73, 2017.

[8] L. Olivianita et al., "Sistem pendukung keputusan kelayakan hasil cetakan buku menggunakan metode moora," no. 9.

[9] A. Septi, R. Anggreani, H. Rotua, B. Hutapea, M. Syahrizal, and N. Kurniasih, "Sistem Pendukung Keputusan Penentuan Handphone Bekas Terbaik Menggunakan Metode MultiObjective Optimization on The Basis of Ratio Analysis ( MOORA )," J. Ris. Komput., vol. 5, no. 1, pp. 61-65, 2018. 